\title{
A META-MODELLING SERVICE PARADIGM FOR CLOUD COMPUTING AND ITS IMPLEMENTATION
}

\author{
F. Cheng ${ }^{1 *}$, S. L. Yang ${ }^{1}$, Ram Akella ${ }^{2} \&$ X.T. Tang ${ }^{3}$ \\ ${ }^{1}$ School of Management \\ Hefei University of Technology, Hefei, China \\ chengfei@usa.com \\ ${ }^{2}$ J ack Baskin School of Engineering \\ University of California, Santa Cruz, United States of America \\ ${ }^{3}$ School of Management \\ University of Science and Technology of China, Hefei, China
}

\begin{abstract}
Service integrators seek opportunities to align the way they manage resources in the service supply chain. Many business organisations can operate new, more flexible business processes that harness the value of a service approach from the customer's perspective. As a relatively new concept, cloud computing and related technologies have rapidly gained momentum in the IT world. This article seeks to shed light on service supply chain issues associated with cloud computing by examining several interrelated questions: service supply chain architecture from a service perspective; the basic clouds of service supply chain; managerial insights into these clouds; and the commercial value of implementing cloud computing. In particular, to show how those services can be used, and involved in their utilisation processes, a hypothetical meta-modelling service of cloud computing is proposed. Moreover, the paper defines the managed cloud architecture for a service vendor or service integrator in the cloud computing infrastructure in the service supply chain: IT services, business services, business processes, which create atomic and composite software services that are used to perform business processes with business service choreographies.
\end{abstract}

\section{OPSOMMING}

Diensintegreeders is op soek na geleenthede om die bestuur van hulpbronne in die diensketting te belyn. Talle organisasies kan nuwe, meer buigsame besigheidprosesse, wat die waarde van ' $n$ diensaanslag uit die kliënt se oogpunt inspan, gebruik. As ' $n$ relatiewe nuwe konsep het wolkberekening en verwante tegnologie vinnig momentum gekry in die IT-wêreld. Die artikel poog om lig te werp op kwessies van die diensketting wat verband hou met wolkberekening deur verskeie verwante vrae te ondersoek: dienkettingargitektuur uit ' $n$ diensoogpunt; die basiese wolk van die diensketting; bestuursinsigte oor sodanige wolke; en die kommersiële waarde van die implementering van wolkberekening. ' $n$ Hipotetiese metamodelleringsdiens van wolkberekening word aanbeveel, veral om te toon hoe die dienste gebruik kan word. Die artikel definieer ook die bestuurde wolkargitektuur vir 'n diensverskaffer of -integreerder in die wolkberekeningsinfrastruktuur van die diensketting: IT-dienste, besigheidsdienste, besigheidsprosesse, wat atoom- en saamgestelde programmatuurdienste voortbring, wat gebruik word om besigheidsprosesse met besigheidsdiensontwerpe uit te voer.

* Corresponding author 


\section{INTRODUCTION}

Service science is the study of value co-creation interactions among entities, known as service systems. Within the emerging service science community, 'service' is often defined as the application of competences (resources) for the benefit of another. Service science can be thought of as integrating the various areas known as service management, service marketing, service operations, service engineering, service computing, service human resource management, service economics, management of service innovation, service supply chain, e-sourcing, and others [33]. Meanwhile, the service supply chain (SSC) is an important foundation for service science. Service supply chain providers service mechanisms for resource sharing, and technological mechanisms for novel business models. For example, service mechanisms can be based on a variety of notions such as purchase, lease, advertising, subscriptions, pay-per-use, transaction fees, taxation, or donations. Accordingly, the real challenge for future pervasive services is the investigation of principles, algorithms, and tools, through which this growing amount of distributed information can be properly represented, organised, aggregated, and made more meaningful, to facilitate its successful exploitation by pervasive services [6].

However, as a general concept, supply chain integration has come in for a lot of criticism in recent years. A myriad constructs and measurements can be found in the literature. A supply chain can be viewed as an organisation plus its supply network, its distribution network, its alliance network, and its end consumers involved in procuring, producing, and delivering products and services to customers [14]. Organisations have traditionally taken a uniform approach to service network design in organising service activities to meet a single service standard. For some, the service network has been designed to meet on average the service requirements of all customers. For others, it has also been designed to satisfy the toughest requirements of a single customer segment. Neither approach can provide the service requirement for each segment in a cost effective fashion. Strategies and methodologies are needed to adapt supply chains to serve differentiated customers in a cost-effective way.

The computing world is currently moving rapidly towards developing software for millions to consume as a service, rather than running it on their individual computers. Cloud computing is an extension of a paradigm wherein the capabilities of business applications are exposed as sophisticated services that can be accessed over a network. Cloud service providers are incentivised by the profits to be made by charging consumers for accessing these services [5]. Since consumers' requirements for cloud services are varied, service providers have to ensure that they can be flexible in their service delivery while keeping the consumers isolated from the underlying infrastructure. The goal of this paper is to help decision-makers understand where cloud computing may be appropriate, and how to describe clouds for the service supply chain.

The remainder of this paper is organised as follows. The results of a literature review of related subjects are presented in Section 2 . In Section 3, a service supply chain architecture from a service perspective is depicted. Section 4 describes the basic clouds of the service supply chain, and develops managerial insights into these clouds. Section 5 describes areas where an organisation needs to understand and evaluate the qualitative changes that a cloud would bring. Section 6 ends with the limitations of this study, and identifies opportunities for future research.

\section{LITERATURE REVIEW}

The service supply chain of today has developed through incremental change to traditional, mostly product-oriented practices, and as such has remained inefficient, ineffective, and insufficient as a guiding model for service supply chains that can successfully address contemporary requirements while making full use of current technological and other opportunities. For most services, elements of both product- and service-oriented operations need to be included [3]. Supply chain management (SCM) research and practices fit naturally 
with this service-centred view, because SCM is concerned with developing and integrating resources to create compellingly competitive value propositions. Information technology can support this service-centred view through distributing information and business processes throughout the value network [26]. Marketing management has also been moving away from its central manufacturing concerns [28]; [16] to concerns with relationships, networks, and service [23]. The strategic mandate for a supplier is to find innovative ways to integrate the resources necessary for service provision [1]. These applied resources may be outsourced to other members (service vendors) of the value network or located in the organisation.

Supply chain management is significantly involved in coordination and collaboration with channel partners, who can be suppliers, intermediaries, third-party providers, or ultimate consumers. One of the strengths of a supply chain oriented collaborative technology is that it is said to foster information- and knowledge-based capabilities [30]. Mabel C. Chou et al. [8] explored a software-focused products and service supply chain, based on the practice of two leading global electronic manufacturing service providers and their major corporate clients. The service strategy literature $([31] ;[19] ;[15])$ and the manufacturing strategy literature ([2];[17]) address the issues of supply chain configuration. Cohen et al. proposed a framework in which a decentralised structure matches a high service criticality, while a centralised structure matches a situation with low service criticality [10]. However, not much attention has been devoted specifically to the configuration of the service supply chain.

In addition, the emerging cloud computing paradigm is rapidly gaining momentum as an alternative to traditional IT, and is highly touted. As noted, there is little hope of obtaining consensus or a standard definition about just what constitutes a 'cloud' [29]. For example, Rochwerger et al. [in 38] proposed the reference model and architecture that systematically address some of those deficiencies and serve as a potential foundation for delivering its services as utilities over the Internet. Papers have emerged in human computer integration venues that have explicitly examined services [7];[11];[35];[27]. Nevertheless, the technology is being implemented commercially by numerous players such as eBay, Amazon, and Google [34]. Most importantly, web services are now being used in the delivery of some aspects of cloud computing; and this promises to deliver not only computing-related functionality but software as well, thanks to other relatively new technologies.

\section{SERVICE SUPPLY CHAIN ARCHITECTURE}

The key to service science is its interdisciplinary qualities. It does not focus only on one aspect of service. Instead, it sees service as a system of interacting parts that include people, technology, and business. Service science draws on ideas from a number of existing disciplines. They include computer science, cognitive science, economics, organisational behaviour, human resources management, marketing and operations research. The aim is to integrate the variety of perspectives that these different fields offer into one coherent whole. To highlight the interdisciplinary nature of the effort, IBM started an initiative in this area that it has called "service science, management and engineering" (SSME), as mentioned earlier [12]. In today's increasingly competitive business marketplace, business organisations face a difficult set of challenges. Some of the many challenges for any organisation - but especially for the information technology organisation - are the following: achieving a competitive advantage through applications and networks, increasing cost predictability, rapidly-changing infrastructure requiring constant technology updates and maintenance, and maintaining a stable corps of information technology (IT) professionals [12]. In response to these challenges, organisations need to make structural, operational, and cultural changes to become more service-oriented. They also need to transform their traditional and tightly-coupled business processes into more loosely-coupled services, and align them vertically with IT services that are sourced by virtual resources [4. The successful realisation of new business and operational models requires a holistic and integrated approach to IT, business process, and organisational structure.

Meanwhile, the service supply chain has developed incrementally while fully using current technological and other opportunities. Much of the technology within supply chains has been 
aligned with the automation of the process. One key element in managing the service supply chain is to have a clear knowledge and understanding of how the service network structure is configured. Similarly, on-demand provision of computing services, along with a cost model that charges customers based on actual service usage, has been an objective in distributed computing research and industry for a while. Cloud computing promises to deliver on this objective: customers are able to rent infrastructure as needed, deploy applications and store data on the infrastructure, and access the application and data via web protocols on a pay-per-use basis [22]. Cloud computing is primarily a new business paradigm for enterprises, rather than just a new technical paradigm in service supply chain management.

To show how those services can be used - and be involved in their processes' use - a hypothetical meta-modelling service of cloud computing can be given. Take, for example, the service supply chain with an IT infrastructure that caters for the needs of customers, service integrators, and service vendors, as shown in Fig. 1. Many activities use software services as their business basis in the service supply chain. These service integrators (SIs) make services accessible to customers or to the market through internet-based interfaces. Clouds aim to outsource the provision of the required computing infrastructure when customer service requests it. This infrastructure is offered as a service to the customer by the service integrator (SI), moving computing resources from the service vendor (SV) to the customer, so that the $\mathrm{SI}$ and the customer can gain flexibility and reduce costs.

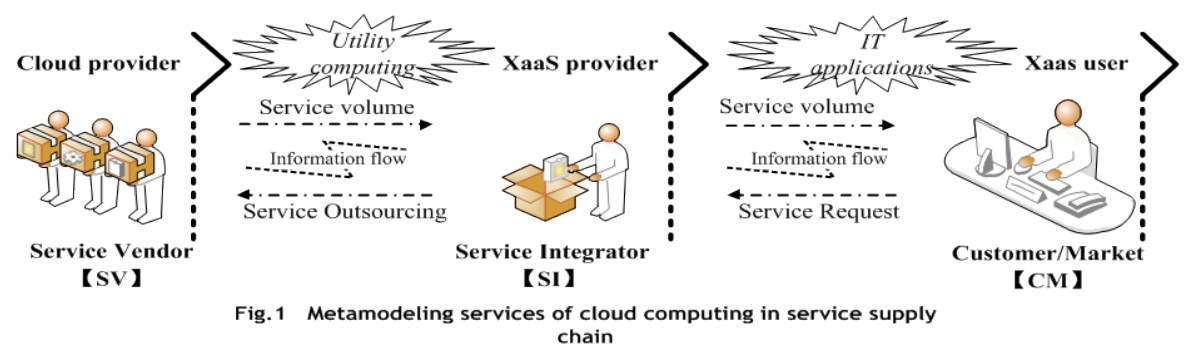

As can be seen from this logical relationship, the service supply chain consists of service vendors (SVs), service integrators (SIs), and customers. The service vendors provide original service products or activities to the Sls who in turn sell value-added integration service to customers. For the meta-modelling services of cloud computing in the service supply chain, cloud vendors (service vendors) provide hardware or application of parts as a service to service integrators. The ' $X$ as a Service' (XaaS) provider (service integrator) provides customers with the capabilities of a simple server (albeit a virtual one) in which the processing, network, and storage resources are controlled dynamically. More sophisticated clouds in XaaS clouds also provide useful management capabilities, programming environments, web service platforms, or access to particular applications. Customers can often acquire or relinquish processing power and storage in minutes, merely by sending a service request to the XaaS provider. The communication channel is virtual, in the sense that the XaaS provider capacity as demanded coming from its infrastructure platform.

\section{CLOUDS FOR THE SERVICE SUPPLY CHAIN}

Cloud computing is another paradigm shift, following the mainframe and client-server shifts before it. It describes a new supplementary consumption and delivery model for IT services based on the internet. It typically involves the provision of dynamically scalable - and often virtualised - resources as a service over the internet. There seem to be many definitions of 'cloud computing', allowing for the extraction of a consensus definition as well as a minimum definition containing the essential characteristics; but they mainly focus on certain aspects of the technology. A study by Vaquero et al. [36] discussed the concept of cloud computing to achieve a full definition of what a 'cloud' is, using the main characteristics typically associated with this paradigm in the literature. In fact, there seems to be no common standard or definition for cloud computing among more than 20 definitions [37]. A more commonly-used definition describes it as clusters of distributed computers that provide 
on-demand resources and services over a networked medium [34]. At a glance, most cloud computing infrastructure consists of reliable services delivered through data centres and built on servers. Clouds often appear as single points of access for all customers' computing needs to meet a specific service-level agreement via web service technologies.

\subsection{Cloud features}

For a service supply chain, the following features are commonly associated with XaaS clouds, which include the cloud features identified in many definitions in the literature. A XaaS user can be a consortium or participant [29].

Resource outsourcing: Instead of consumers providing their own hardware, the cloud vendor assumes responsibility for hardware acquisition and maintenance.

Large numbers of service volumes: Clouds are typically constructed using large numbers of different service volumes. As a result, the cloud vendor can more easily add capacity and more rapidly align volumes as needed, compared with having service volumes in multiple circumstances. Generally speaking, these service volumes are as homogeneous as possible, in terms of both configuration and location in the service supply chain.

Utility computing: The customer requests additional resources as needed, and similarly releases these resources when they are not needed according to their self-service demands. Different clouds offer different sorts of resources.

Virtualisation: Virtualisation is a key enabler of architecture as well as cloud applications. Hardware resources in clouds are usually virtual resources, shared by multiple services requests to improve efficiency. That is, several lightly-used logical resources can be supported by the same physical resource.

High level services: Clouds suffer a certain lack of high level services, which is probably related to the relative immaturity of the paradigm. Clouds leave these issues to be treated at the application level, although federated clouds will probably require several mechanisms to deal with these topics.

Scalability and self-management: Clouds are free programmers dealing with scalability issues. Clouds offer the automatic resizing of virtualised hardware resources. Scalability and self-management is simpler in a single administrative domain, but many problems can arise across organisational frontiers.

\subsection{Cloud infrastructure for the service supply chain}

As discussed above, when multiple customers' service requests from the market need to share data or a platform, the service integrators face the management difficulties of either heterogeneous underpinnings or being forced to acquire uniform systems. They still need to support hardware conventionally, with substantial delays and limited economy of scale. The service integrators deal with customers' service requests that may be hard to increase or decrease rapidly in capacity. However, clouds offer many management services similar to grids. Clouds also offer economies of scale and the ability to adj ust service volume variations.

In the service supply chain, the service integrators (XaaS providers) effectively sell computation and storage resources as service commodities, providing customers with the illusion of a single virtual machine or cluster. For example, the customers control computational and storage capacity by sending a service request to add or subtract resources as needed, based on the Google Apps application platform. The release capacity is typically measured in minutes. To help explain how cloud computing can be used in the service supply chain, it is valuable to consider an architectural view of the building blocks typically found in a service supply chain. This framework is based on using software components to create atomic and composite software services that are used to perform business processes with business service choreographies, as shown in Figure 2. 


\begin{tabular}{|c|c|}
\hline \multicolumn{2}{|c|}{ Data and information architecture/security, management } \\
\begin{tabular}{|c|c|}
\hline IT Services & Business service \\
\hline $\begin{array}{c}\text { Public and private clouds } \\
\text { Semantic service transformation }\end{array}$ & Business functionalities \\
\hline \hline Business processes & Business conceptual design \\
\hline $\begin{array}{c}\text { Service integration/ } \\
\text { composition/choregraphy }\end{array}$ & \\
\hline
\end{tabular}
\end{tabular}

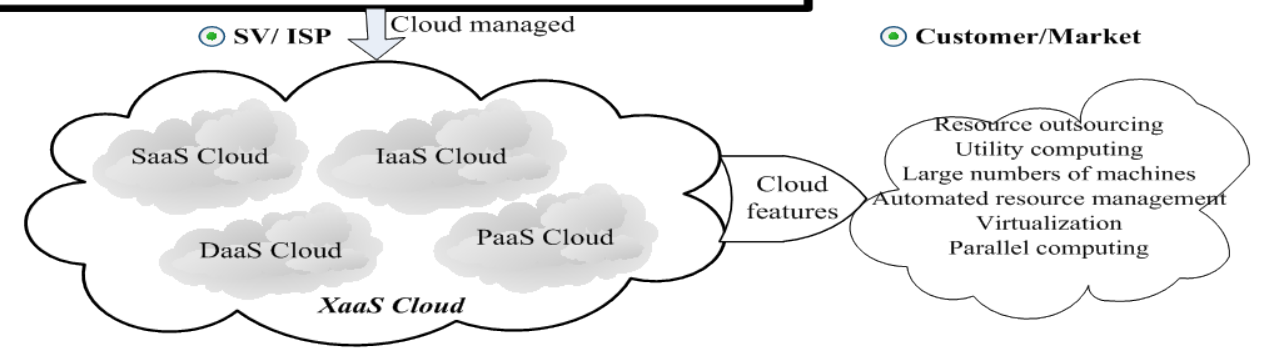

Fig.2 infrastructure of cloud computing in the service supply chain

We define the architecture of the cloud managed for SV or SI in infrastructure of cloud computing based on the service supply chain: IT services, business services, business processes. The maj or functions (supporting or core) of a business - such as human resources or accounting - are defined as 'coarse grained services', and are referred to as 'business services' in cloud management. It can be divided into those that are common, industry-specific, and company-specific. These descriptions can be used to find services from the marketplace that may fulfill the requirements. The IT services represent the services that are offered in the cloud. Innovative approaches in service search technology are required to combine techniques, and to be highly scalable to index the many services that will be available in the cloud, allowing service seekers to offer potentially diverse constraints, transfers, and protection. Indeed, there is a need for approaches to tag the data directly with security and privacy policies so that the proper technical controls can be employed by the various clouds providers. Finally, the business process is a representation of the selection, design, integration, and composition of services that meet the requirements of the business environment outlined above. Emerging cloud services integration, such as that offered by Bungee Connect, has taken the first step by providing pre-defined connectors. However, it is inadequate for unsupported applications or complexes. To enable scaling of such approaches to the diversity of applications on the internet, a service integration development platform and marketplace has to be built.

Cloud computing refers to both the applications delivered as services over the internet, and the hardware and systems software in the data centres that provide those services. The services themselves have long been referred to as ' $X$ as a Service' (XaaS); values of $X$ that we have seen in print include infrastructure, software, database, and platform. However, through understanding the type of service offered by cloud computing, one begins to understand what this new approach is all about. Depending on the type of provided capability, we can summarise the four main types of service that can be offered by the cloud as follows (see Figure 2).

Infrastructure as a Service (laaS): the SI manages a large set of computing resources, such as storage and processing capacity. Based on a service request from a customer, the $\mathrm{SI}$ is able to split, assign, and dynamically resize these resources to build ad-hoc systems, including remote delivery through the internet of a full computer infrastructure (virtual computers, servers, storage devices, etc.). At present, some companies are billed for their usage following a utility computing model, where usage of resources is metered. For example, HP flexible computing services provide computing and storage infrastructure as services for businesses. Amazon often offers EC2 (Elastic Compute Cloud) for computing power for small businesses and individual consumers where they can deploy and run their programs. 
Software as a Service (SaaS): Under this cloud, software applications are delivered as a service over the internet, and offered as services rather than as software packages that are purchased by individual customers. This is an alternative to locally-run applications. There are services that could potential interest SIs and SVs. This type of cloud service offers complete application functionality, installation, and maintenance of software in a local infrastructure. An example of a commercial application in this category is Salesforce.com, which offers its CRM application as a service on a pay-per-use or on a monthlysubscription-per-use basis.

Database as a service (DaaS): Daas is a viable model with a good chance of emerging as a successful commercial offering for some applications. DaaS often adopts a multi-tenant architecture, where the data of many customers is kept in the same physical table on the cloud. An example of such a service is Amazon's SimpleDB, an internet-based database service that provides users with tools for application development, creating and loading tables, and performing queries and transactions. Also, in most cases, the database structure is not relational. The database service provider offers seamless mechanisms for organisations to create, store, and access their databases. For example, customers wishing to access data will now do so using the hardware and software of the service provider instead of their own organisation's computing infrastructure. This would alleviate the problem of purchasing, installing, maintaining, and updating software and administering the system.

Platform as a Service (PaaS): PaaS is a paradigm for delivering operating systems and associated services over the internet without downloads or installation, providing facilities to support the entire application development lifecycle including design, implementation, debugging, testing, deployment, operation, and support of rich web applications and services on the internet. An example of a platform in this category is the Google Apps engine. Services can be obtained from diverse sources that cross international boundaries. Meanwhile, initial and ongoing costs can be reduced by the use of infrastructure services from a single vendor, rather than maintaining multiple hardware facilities that often perform duplicate functions caused by incompatibility problems. However, limited platform interoperability, and the limitations of programming platforms in supporting capabilities, are maj or concerns for those using these platforms. Nevertheless, overall expenses can be minimised by unifying the programming development efforts.

\subsection{Concerns related to cloud computing}

Cloud computing, as we noted earlier, is an emerging computing service paradigm. But there are uncertainties and concerns about the maturity of the technology, mainly vendor lock, performance, latency, transparency, security, privacy, reliability, etc.

In some cases, a service vendor may wish to include the right - but not the obligation - to stop the delivery of services, when the cost of doing such business becomes unprofitable. Option pricing methods typically emphasise the variations in the underlying costs of service delivery, and the extent to which they may become unfavourable to the vendor [12]. The application of value-at-risk thinking in the service management context suggests the vendor's desire to identify the value-optimising duration of a service contract [20]. If customers are dissatisfied with one cloud computing service, or of the SI goes out of business, then customers cannot necessarily transfer their services easily and inexpensively to another SI or bring their clouds back in-house. Instead, if customers or a firm bring their service clouds in-house, they are under pressure to hire employees with the skills to work with the technology, and to reformat or transfer service applications to a new SI - a potentially complex process.

IT managers are likely to be wary of surrendering control of their resource to outside providers who can change the underlying technology without the customers' consent. Issues relating to performance and latency are also cited as problematic [34]. Meanwhile there are no cloud computing standards for processes such as APIs processing data import and export. There are also difficulties with limiting the usage of data and applications in different systems. 
Service vendors are trying to address their concern about capabilities by having their service volume audited in advance by the Sl, and documenting procedures designed to address customers' demands. The SI can show who has access to data, and how to keep unauthorised personnel from retrieving service information. For cloud users, reliability may be an important problem. Cloud computing has not always been reliable. For example, Salesforce.com left customers without service for six hours on 12 February 2008. And Amazon's S3 (Simple Storage Service) and EC2 (Elastic Compute Cloud) services suffered a three-hour outage three days later [24]. Although most service vendors provide service credits for outages, resulting in missing business information that may threaten service opportunities.

In addition, internet connections for cloud computing can be a serious problem for users. For example, broadband internet connections are not fast or reliable enough for cloud computing to be dependable. If these are not available in every place, they are far from the service's central office at some times and in some areas. Also, there are not yet enough maj or cloud services providers, reducing the level of customer choice and marketplace competition.

\section{THE COMMERCIAL VALUE OF CLOUD IMPLEMENTATION}

Service providers and consumers need to establish efficient service products and the exchange of value in a way that emphasises co-creation [9]. Many see the huge potential of the technology to reduce the cost of IT through a pay-as-you-go model that will offer significant cost advantages, according to one view [25]. This would seem to be the case for cloud computing and management approaches. At the macro level, the viability of cloud computing remains to be seen. For example, even though other new technological approaches appear to be valuable, it is uncertain how long will it actually take for customers or the market to leverage the new infrastructures, platforms, business processes, and strategies to the point where sufficient value is added to recoup the large costs that are involved. This is true in spite of their inherent capacity to produce paradigm changes that should produce value in the long run; and so getting the timing right is important both within a firm, and also with respect to the market games it is forced to play with its external competitors. [32]

The clouds infrastructure presents itself as an opportunity to improve the management outgoings for both SIs and customers. The solutions of XaaS clouds infrastructure facilitate the easing of cash-flow management for SIs, as the cloud pricing model has minimal upfront cost, and is also minimises the variability of expenditure on electricity. XaaS clouds infrastructure solutions also uncover many opportunities for managing income for customers, as new pricing models can be offered to them. This is a benefit, as customers can be offered more choice over how they want to pay. Alternatively the SI can choose to get the infrastructure outsourcer to bill their customers directly, reducing the Sl's administrative burden. Meanwhile, XaaS clouds infrastructure solutions present an opportunity for service vendors and service integrators to create new service offerings that better fit the customers' need in terms of scalability and cost effectiveness. For service vendors facing potentially satisfying challenges, it is a benefit that would not have existed without the migration to cloud infrastructure. XaaS clouds infrastructure solutions present an opportunity for Sls to create new service offerings that may appeal to a larger market share, due to the clouds infrastructure's properties of scalability and its cost effectiveness. For a service vendor, support managers and engineers have opportunities to develop new skills in clouds that provide administration, which will expand their existing skill sets and experience with new knowledge of managing a technology that will be in demand. This is also beneficial to Sis, as it will expand their existing skill sets and experience, enabling their career progression.

The cost advantage of cloud computing is not just related to how much cloud providers or users can save by not buying and installing hardware and software and using less power. Users of cloud computing are more likely to reduce their carbon footprint significantly [34]. Energy costs and virtualised services offered by cloud computing may become especially appealing in an environment where there is a growing concern about the carbon footprint. In the UK, for example, increasingly stringent regulations (such as the carbon reduction commitment and 
the EU's energy-using products directive) are likely to put pressure on educational establishments to make ICT more sustainable [18]. In addition, the business environment and the organisational culture of different enterprises can play a big role in mitigating success and realising the commercial value of implementing cloud computing in the service supply chain.

\section{CONCLUSION AND FUTURE WORK}

Cloud computing is a disruptive technology that is set to change how IT systems are deployed, because of its apparently cheap, simple, and scalable nature [21]. The main contribution of this paper is our unique approach to the configuration meta-modeling of a service supply chain, based on cloud computing. To demonstrate how those services can be utilised, and to show the processes involved in their utilisation, a hypothetical meta-modelling service of cloud computing can be used. Moreover, to perform business processes with business service choreographies, we define the architecture of the cloud that is managed for SV or SI in the infrastructure of cloud computing in a service supply chain. We have analysed the commercial value of cloud implementation according to three categories: opportunities to manage income for customers, opportunities for service vendors and service integrators to create new service offerings, and opportunities for Sls to create new service offerings. In addition, the paper refers to the green credentials of the clouds in a service supply chain.

The paper presents only some initial academic research to meet the needs of the service supply chain. Maj or challenges to the service supply chain that should be investigated further include: (1) the integration of technological research and management into the service supply chain that presents exhaustive research on quantitative, qualitative, and experimental methods, case and field studies, and design science approaches and processes; (2) discussion of technological obstacles (e.g. software portability, cloud immaturity, and transition obstacles) in cloud computing that is suitable for a service supply chain; (3) some of the policies and criteria issues of data protection and data security according to different interpretations. Those problems would be good candidates for future research.

\section{ACKNOWLEDGEMENT}

This research is supported by a research grant from the Natural Science Foundation of China. The authors acknowledge the Institute of Computer Network systems and the Preparatory Office of Service Science Research Center at Hefei University of Technology for their support of this research. The authors also thank the anonymous referees for their valuable suggestions.

\section{REFERENCES}

[1] Ballantyne, D., \& Varey, R.J. 2008. The service-dominant logic and the future of marketing, J ournal of the Academy of Marketing Science, 36(1), pp 11-14

[2] Bozarth, C. \& McDermott, C. 1998. Configurations in manufacturing strategy: A review and directions for future research, J ournal of Operations Management, 16(4), pp 427-439

[3] Brady, M. \& Fellenz, M.R. 2007. The service paradox: Supporting service supply chains with product-oriented ICT. Available at SSRN: http:// ssrn. com/ abstract=995127, pp 1-6

[4] Brown, G.W., Demirkan, H., Goul, M. \& Mitchell, M. 2006. Towards the service-oriented enterprise vision: Bridging industry and academics, American Conference on Information Systems, pp 4-6. Acapulco, Mexico.

[5] Buyya, R., Yeo, C.S., Venugopal, S., Broberg, J . \& Brandic, I. 2009. Cloud computing and emerging IT platforms: Vision, hype, and reality for delivering computing as the 5th utility, Future Generation Computer Systems, 25(6), pp 599-616

[6] Castelli, G., Mamei, M. \& Zambonelli, F. 2008. Engineering contextual knowledge for autonomic pervasive services, Information and Software Technology, 50(1-2), pp 36-50

[7] Chen, J.V., Yen, D.C. \& Chen, K. 2009. The acceptance and diffusion of the innovative smart phone use: A case study of a delivery service company in logistics, Information \& Management, 46(4), pp 241-248

[8] Chou, M.C., Ye, H., Yuan, X., Cheng, Y.N. \& Chua, L. 2006. Analysis of a software-focused products and service supply chain, IEEE Transactions on Industrial Information, 2(4), pp 295-302

[9] Chung, J. \& Chao, K. 2007. A view on service-oriented architecture, Service Oriented Computing and Applications, 1(2), pp 93-95 
[10] Cohen, M.A., Cull, C., Lee, H.L. \& Willen, D. 2000. Saturn's supply-chain innovation: High value in after-sales service, Sloan Management Review, 41(4), pp 93-101

[11] Cyr, D., Hassanein, K., Head, M. \& Ivanov, A. 2007. The role of social presence in establishing loyalty in e-Service environments, Interacting with Computers, 19(1), pp 43-56

[12] Demirkan, H. 2002. Supply chain management of application service providers: Coordination strategies and queuing effects. Thesis, University of Florida, Gainesville.

[13] Demirkan, H., Kauffman, R.J., Vayghan, J.A., Fill, H.G., Karagiannis, D. \& Maglio, P.P. 2008. Service-oriented technology and management: Perspectives on research and practice for the coming decade, Electronic Commerce Research and Applications, 7(4), pp 356-376

[14] Deshpande, V. 2000. Supply chain coordination with service differentiated customer classes. Thesis, University of Pennsylvania, Pennsylvania.

[15] Fitzsimmons, F. 2009. Service management: Operations, strategy, information technology, European J ournal of Control, 15(1), pp 45-48

[16] Grönroos, C. 2000. Service management and marketing: A customer relationship management approach, Baffins Lane, Chichester, J ohn Wiley \& Sons, Ltd.

[17] Hill, T. \& Hill, A. 1995. Manufacturing strategy: Text and cases, 1st edition: Palgrave.

[18] J ames, P. \& Hopkinsons, L. 2009. Sustain ICT in further and higher education: Final report, A report for J oint Information Services Committee.

[19] J ohansson, P. \& Olhager, J. 2006. Linking product-process matrices for manufacturing and industrial service operations, International J ournal of Production Economics, 104(2), pp 615-624

[20] Kauffman, R.J ., \& Sougstad, R. 2008. Value-at-risk in services-oriented systems and technology investments: A frame work for managing project portfolio uncertainties, International J ournal of Services Sciences, 1(3-4), pp 225-246

[21] Khajeh-Hosseini, A., Greenwood, D. \& Sommerville, I. 2010. Cloud migration: A case study of migrating an enterprise IT system to laaS. Imprint.

[22] Klems, M., Nimis, J . \& Tai, S. 2009. Do clouds compute? A framework for estimating the value of cloud computing, Springer.

[23] Larson, P.D., Poist, R.F. \& Halldórsson, Á. 2007. Perspectives on logistics vs. SCM: A survey of SCM professionals, J ournal of Business, 28(1), pp 1-24

[24] Leavitt, N. 2009. Is cloud computing really ready for prime time?, Computer, 42(1), pp 15-20

[25] Lin, G., Fu, D. \& Zhu, J . 2009. Cloud computing: IT as a service, IT professional, 11(2), pp 10-13

[26] Lusch, R.F., Vargo, S. L. \& Tanniru, M. 2010. Service, value networks and learning, J ournal of The Academy of Marketing Science, 38(1Sp. Iss. SI), pp 19-31

[27] Magoulas, G.D. \& Chen, S. 2006. Human factors in personalised systems and services, Interacting with Computers, 18(3), pp 327-330

[28] Peterson, M. \& Ekici, A. 2007. Consumer attitude toward marketing and subjective quality of life in the context of a developing country, J ournal of Macromarketing, 27(4), pp 350-359

[29] Rosenthal, A., Mork, P., Li, M.H., Stanford, J ., Koester, D. \& Reynolds, P. 2009. Cloud computing: A new business paradigm for biomedical information sharing, J ournal of Biomedical Informatics (in press).

[30] Rust, R.T., \& Espinoza, F. 2006. How technology advances influence business research and marketing strategy, J ournal of Business Research, 59(10-11), pp 1072-1078

[31] Silvestro, R., Fitzgerald, L., Johnston, R. \& Voss, C. 1992. Towards a classification of service processes, International J ournal of Service Industry Management, 3(3), pp 62-75

[32] Smit, H. \& Ankun, L. 1993. A real options and game theoretic approach to corporate investment strategy under competition, Financial Management, 22(3), pp 241-250

[33] Spohrer, J., Anderson, L.C., Pass, N.J ., Ager, T. \& Gruhl, D. 2008. Service science, J ournal of Grid Computing, 6(3), pp 313-324.

[34] Sultan, N. 2009. Cloud computing for education: A new dawn? International J ournal of Information Management, 30, pp 109-116

[35] Van Dijk, G., Minocha, S. \& Laing, A. 2007. Consumers, channels and communication: Online and offline communication in service consumption, Interacting with computers, 19(1), pp 7-19

[36] Vaquero, L. M., Rodero-Merino, L., Caceres, J . \& Lindner, M. 2008. A break in the clouds: Towards a cloud definition. ACM SIGCOMM Computer Communication Review, 39(1), pp 50-55

[37] Voas, J . \& Zhang, J . 2009. Cloud computing: New wine or just a new bottle? IT Professional, 11(2), pp. $15-17$

[38] Wolfsthal, Y., Elmroth, E., Ben-Yehuda, M. \& Emmerich, W. 2009. The reservoir model and architecture for open federated cloud computing, J ournal of Research and Development, 53(4), pp 1-17 